\title{
Identification of mutations that prevent the development of Alzheimer's disease
}

Perry G. Ridge

Celeste M. Karch

Simon Hsu

Ivan Arano

Craig C. Teerlink

Mark T. W. Ebbert

Josue D. Gonzalez Murcia

James M. Farnham

Anna R. Damato

Mariet Allen

Xue Wang

Oscar Harari

Victoria M. Fernandez

Rita Guerreiro

Jose Bras

John Hardy

Ronald Munger

Maria Norton

Celeste Sassi

Andrew Singleton

Steven G. Younkin

Dennis W. Dickson

Todd E. Golde

Nathan D. Price

Nilüfer Ertekin-Taner

Carlos Cruchaga

Alison M. Goate

Christopher Corcoran

JoAnn Tschanz

Lisa A. Cannon-Albright

John S. K. Kauwe

Video Abstract 
Keywords: RAB10, protective variants, whole genome sequencing, Utah Population Database, linkage analysis, Alzheimer's disease, Alzheimer's Disease Neuroimaging Initiative, Cache County Study on Memory Health and Aging, AD resilience, genetics of Alzheimer's, APOE e4, SAR1A, amyloid beta, amyloid precursor protein, rare risk variants, pedigree analysis, gene discovery, genomics, genome medicine, genetic resilience

Posted Date: September 19th, 2019

DOl: https://doi.org/10.21203/rs.2.14930/v1

License: (a) (i) This work is licensed under a Creative Commons Attribution 4.0 International License. Read Full License 


\section{Abstract}

Most genetic studies of Alzheimer's disease compare patient DNA to controls to identify mutations that increase disease risk. That approach has identified some risk variants, but none have led to effective treatments, and most of the genetic contributors are still unknown. Now, a team of researchers is tackling the problem from the opposite side, asking why some high-risk elderly people don't have Alzheimer's - a strategy that has discovered a protective mutation in a gene that may be a good drug target. To find protective mutations for Alzheimer's, the scientists first searched the Utah Population Database for families with above-average rates of Alzheimer's that also had at least four people who were resilient to the disease - that is, they were cognitively normal, despite being 75 years old or older, and having the APOE e4 allele, which increases risk more than 5-fold per copy. The Utah Population Database is a unique dataset with more than 7 million people, including descendants from the original founders of Utah, many of whom have genealogical data going back multiple generations. The group found 5 families that matched the criteria and had DNA samples from Alzheimer's patients and Alzheimer's-resilient people. The team then used linkage analysis to identify areas of the genome associated with resilience in each family. They found variants in two genes, RAB10, and SAR1A, that were plausible protective variants. Both variants are rare and both genes interact with amyloid precursor protein, which is thought to be key in the development of the disease. The researchers checked two separate datasets to confirm this finding, and saw once again that the RAB10 variant was associated with reduced Alzheimer's risk. To see how this variant might be protective, the scientists altered expression of RAB10 in neuroblastoma cells. Knockdown resulted in amyloid beta secretion patterns that are associated with protection from Alzheimer's. Consistent with these findings and a possible role in the disease, the team also found that RAB10 expression was significantly higher in the brains of Alzheimer's patients. The results suggest that RAB10 may be an ideal drug target to prevent Alzheimer's. If scientists can find a way to reduce its expression or limit its activity, that could mimic the effect of the variant in resilient people, offering others that protection. Importantly, the pedigree-based method used in this study could be extremely useful in identifying other resilient gene candidates in the future. 